\title{
Stability of $k$-step fixed point iterative methods for some Prešić type contractive mappings
}

\section{Vasile Berinde ${ }^{1 *}$ and Mădălina Păcurar ${ }^{2}$}

\section{"Correspondence:} vberinde@ubm.ro

'Department of Mathematics and Computer Science, North University of Baia Mare, Victorie1 76, Baia Mare, 430072, Romania

Full list of author information is available at the end of the article

\begin{abstract}
We introduce the concept of stability of a $k$-step fixed point iterative method $x_{n+1}=T\left(x_{n}, x_{n-1}, \ldots, x_{n-k+1}\right), n \geq k-1$, and study the stability of this equation for mappings $T: X^{k} \rightarrow X$ satisfying some Prešić type contraction conditions. Our results naturally extend various stability results of fixed point iterative methods in literature, from contractive self-mappings $T: X \rightarrow X$ to Prešić type contractive mappings $T: X^{k} \rightarrow X$. Illustrative examples of both stable and unstable fixed point iterations are also presented.
\end{abstract}

MSC: $47 \mathrm{H} 09 ; 47 \mathrm{H} 10 ; 54 \mathrm{H} 25$

Keywords: metric space; contractive mapping; fixed point; k-step fixed point iterative method; stability

\section{Introduction}

Let $(X, d)$ be a metric space and $T: X \rightarrow X$ a self-mapping. Denote by $\operatorname{Fix}(T):=\{x \in X$ : $T x=x\}$ the set of fixed points of $T$. If $(X, d)$ is complete and $T$ is a contraction, i.e., there exists a constant $\alpha \in[0,1)$ such that

$$
d(T x, T y) \leq a d(x, y), \quad \text { for all } x, y \in X
$$

then, by the well-known Banach contraction mapping principle, we know that $\operatorname{Fix}(T)=\{p\}$ and that, for any $x_{0} \in X$, the Picard iteration, that is, the sequence defined by $x_{n+1}=T x_{n}$, $n=0,1, \ldots$, converges to $p$, as $n \rightarrow \infty$.

When applying contraction mapping principle for solving concrete nonlinear problems, because of rounding errors, numerical approximations of functions, derivatives or integrals, discretization etc., instead of the theoretical sequence $\left\{x_{n}\right\}_{n=0}^{\infty}$, defined by the given iterative method, we practically work with an approximate sequence $\left\{y_{n}\right\}_{n=0}^{\infty}$, satisfying the following approximation bounds:

$$
y_{0}:=x_{0}, \quad d\left(y_{1}, T y_{0}\right) \leq \epsilon_{1}, \quad \ldots, \quad d\left(y_{n}, T y_{n-1}\right) \leq \epsilon_{n}, \quad \ldots
$$

where the positive quantity $\epsilon_{n}$ can be interpreted as the 'round-off error' of $x_{n}$; see [1].

Under these circumstances, the problem of the numerical stability of Picard iteration is whether the approximate sequence $\left\{y_{n}\right\}_{n=0}^{\infty}$ still converges to the fixed point $p$ of $T$, provided that $\epsilon_{n} \rightarrow 0$ or $\sum_{n=1}^{\infty} \epsilon_{n}<\infty$.

C2014 Berinde and Păcurar; licensee Springer. This is an Open Access article distributed under the terms of the Creative Commons Attribution License (http://creativecommons.org/licenses/by/2.0), which permits unrestricted use, distribution, and reproduction in any medium, provided the original work is properly cited. 
This question has been answered in the positive, in the case of contraction condition (1), by Ostrowski [2], who established the first stability result for a fixed point iteration procedure, by using the following estimate:

$$
d\left(y_{n}, p\right) \leq \frac{\alpha^{n}}{1-\alpha} d\left(x_{0}, x_{1}\right)+\sum_{k=1}^{n} \alpha^{n-k} \epsilon_{k}, \quad n=0,1,2, \ldots
$$

from which easily follows that $y_{n} \rightarrow p$, provided $\epsilon_{n} \rightarrow 0$.

In 1988, Harder and Hicks [3, 4] introduced the notion of stability for a general fixed point iteration procedure and started a systematic study of this concept, thus obtaining various stability results for Picard iteration that extended Ostrowski's theorem to mappings satisfying more general contractive conditions and also established some stability results for other fixed point iteration procedures (Mann iteration, Ishikawa iteration, Kirk iteration) in the class of Banach contractions, Zamfirescu operators etc.

Further, some authors, see [1,5-17], continued the study of the stability of Picard and some other fixed point iterations for various general classes of contractive self-mappings $T$. Very recently, Rus $[18,19]$ introduced some alternative concepts of stability for fixed point iterative methods.

On the other hand, the contraction mapping principle has been extended by Prešić [20] to mappings $T: X^{k} \rightarrow X$ satisfying a contractive condition that include (1) in the particular case $k=1$. Some other Prešić type fixed point theorems have been obtained in [21-26], in the case $T$ satisfies more general contractive type conditions, while in [27, 28], and [29], some applications to nonlinear cyclic systems of equations and difference equations are obtained.

As for the $k$-step fixed point iterative methods associated to Prešić type contractive conditions do not exist corresponding stability results, yet, the main aim of this paper is to fill this gap and to introduce an appropriate concept of stability and then establish some stability results. The relationship of our notion of stability to other existing concepts of stability, mainly drawn from the theory of difference equations, is also discussed.

The stability results we shall obtain in this way are extremely general. They unify, extend, generalize, enrich, and complement a multitude of related results from recent literature. Illustrative examples of both stable and unstable fixed point iterative sequences are given.

The paper is organized as follows: in Section 2 we summarize some fixed point theorems for mappings satisfying Prešić type contractive conditions, in Section 3 we present the basic concepts and results concerning the stability of fixed point iteration procedures associated to self-mappings that satisfy explicit contractive conditions. In Section 4, the main stability results of this paper are presented. In Section 5, we end this paper by presenting three detailed examples of stable (Examples 1 and 2) and unstable (Example 3) fixed point iterations.

\section{Fixed point theorems for Prešić type mappings}

All the stability results mentioned in the previous section were basically established in connection with a corresponding fixed point theorem: Banach, Kannan, Chatterjea, Zamfirescu etc.; see for example [15] for more details.

We start by presenting one of the most interesting generalizations of Banach's contraction mapping principle for mappings $T: X^{k} \rightarrow X$, obtained in 1965 by Prešić [20], which 
will be fundamental in establishing our stability results for $k$-step fixed point iterative methods in the present paper.

Theorem 1 (Prešić [20], 1965) Let $(X, d)$ be a complete metric space, $k$ a positive integer, $\alpha_{1}, \alpha_{2}, \ldots, \alpha_{k} \in \mathbb{R}_{+}, \sum_{i=1}^{k} \alpha_{i}=\alpha<1$ and $T: X^{k} \rightarrow X$ a mapping satisfying

$$
d\left(T\left(x_{0}, \ldots, x_{k-1}\right), T\left(x_{1}, \ldots, x_{k}\right)\right) \leq \alpha_{1} d\left(x_{0}, x_{1}\right)+\cdots+\alpha_{k} d\left(x_{k-1}, x_{k}\right)
$$

for all $x_{0}, \ldots, x_{k} \in X$.

Then:

(1) $T$ has a unique fixed point $x^{*}$, that is, there exists a unique $x^{*} \in X$ such that $f\left(x^{*}, \ldots, x^{*}\right)=x^{*}$

(2) the sequence $\left\{x_{n}\right\}_{n \geq 0}$ defined by

$$
x_{n+1}=T\left(x_{n}, \ldots, x_{n-k+1}\right), \quad n=k-1, k, k+1, \ldots
$$

converges to $x^{*}$, for any $x_{0}, \ldots, x_{k-1} \in X$.

It is easy to see that, in the particular case $k=1$, from Theorem 1 we get exactly the well-known Banach contraction mapping principle, while the $k$-step iterative method (4) reduces to Picard iteration:

$$
x_{n+1}=T\left(x_{n}\right), \quad n=0,1,2,3, \ldots
$$

Theorem 1 and other similar results, like the ones in [21,23, 24, 26], have important applications in the iterative solution of nonlinear equations, see [30] and [28, 31,32], as well as in the study of global asymptotic stability of the equilibrium for nonlinear difference equations; see the very recent paper [29].

An important generalization of Theorem 1 was proved by Rus [26], for operators $T$ fulfilling the more general condition

$$
d\left(T\left(x_{0}, \ldots, x_{k-1}\right), T\left(x_{1}, \ldots, x_{k}\right)\right) \leq \varphi\left(d\left(x_{0}, x_{1}\right), \ldots, d\left(x_{k-1}, x_{k}\right)\right),
$$

for any $x_{0}, \ldots, x_{k} \in X$, where $\varphi: \mathbb{R}_{+}^{k} \rightarrow \mathbb{R}_{+}$satisfies certain appropriate conditions.

Another important generalization of Prešićs result was recently obtained by Cirić and Prešić in [21], where, instead of (3) and its generalization (6), the following contraction condition is considered:

$$
d\left(T\left(x_{0}, \ldots, x_{k-1}\right), T\left(x_{1}, \ldots, x_{k}\right)\right) \leq \lambda \max \left\{d\left(x_{0}, x_{1}\right), \ldots, d\left(x_{k-1}, x_{k}\right)\right\},
$$

for any $x_{0}, \ldots, x_{k} \in X$, where $\lambda \in(0,1)$.

Other general Prešic type fixed point results have been very recently obtained by the second author in $[22,23,25,33]$ based on the contractive condition (18), studied in [23], which is more general than (7), (6) and (3). 


\section{Some useful lemmas}

In order to obtain simple and short proofs for our main results in this paper we shall need some auxiliary lemmas. A proof of the following lemma can be found in [34]; see also [35].

Lemma 1 (Cauchy) Let $\left\{a_{n}\right\}_{n=0}^{\infty},\left\{b_{n}\right\}_{n=0}^{\infty}$ be sequences of nonnegative numbers satisfying

$$
\text { (i) } \quad \lim _{n \rightarrow \infty} a_{n}=0 ; \quad \text { (ii) } \quad \sum_{k=0}^{\infty} b_{k}<\infty \text {. }
$$

Then

$$
\lim _{n \rightarrow \infty} \sum_{k=0}^{n} a_{k} b_{n-k}=0 .
$$

We note that by Lemma 1 we find that the second term in (2) converges to zero:

$$
\sum_{k=1}^{n} \alpha^{n-k} \epsilon_{k} \rightarrow 0 \quad \text { as } n \rightarrow \infty
$$

Lemma 2 Let $k$ be a positive integer and $\left\{a_{n}\right\}_{n=0}^{\infty},\left\{b_{n}\right\}_{n=0}^{\infty}$ two sequences of nonnegative real numbers satisfying the inequality

$$
a_{n+1} \leq \alpha_{1} a_{n}+\alpha_{2} a_{n-1}+\cdots+\alpha_{k} a_{n-k+1}+b_{n}, \quad n \geq k-1
$$

where $\alpha_{1}, \ldots, \alpha_{k} \in[0,1)$ and $\alpha_{1}+\cdots+\alpha_{k}<1$. If $\lim _{n \rightarrow \infty} b_{n}=0$, then $\lim _{n \rightarrow \infty} a_{n}=0$.

Proof For simplicity, we prove lemma for $k=2$, when we denote $\alpha_{1}:=\alpha$ and $\alpha_{2}:=\beta$. All arguments used below work unchanged in the general case, too.

We first show that if the sequence $\left\{u_{n}\right\}_{n=0}^{\infty}$ is given by $u_{0}=1, u_{1}=\alpha$ and

$$
u_{n+1}=\alpha u_{n}+\beta u_{n-1}, \quad n \geq 1,
$$

then the series $\sum_{n=0}^{\infty} u_{n}$ converges.

Indeed, the characteristic equation corresponding to the linear difference equation (9) has two distinct real roots, $r_{1}, r_{2} \in(-1,1)$, since, if we denote $f(r):=r^{2}-\alpha r-\beta$, we have $f(-1)>0, f(1)>0$.

Hence, $u_{n}=c_{1} r_{1}^{n}+c_{2} r_{2}^{n}$, where $c_{1}, c_{2}$ are two constants, and so the convergence of $\sum_{n=0}^{\infty} u_{n}$ follows by the convergence of the geometric progression series $\sum_{n=0}^{\infty} q^{n}$, with $-1<q<1$.

Note that in the general case, the characteristic equation

$$
r^{k}-\alpha_{1} r^{k-1}-\cdots-\alpha_{k-1} r-\alpha_{k}=0
$$

has all its roots (not always real) in absolute value in the interval $[0,1)$, by virtue of a consequence of the Rouché theorem, see [36], which reads as follows.

Let $p(x)=a_{0}+a_{1} x+\cdots+a_{n} x^{n}$ be a polynomial with complex coefficients $a_{0}, a_{1}, \ldots, a_{n}$ such that $a_{n} \neq 0$. Then there are exactly $n$ (counted with multiplicity) roots of absolute 
value less than $R$, where

$$
R=\max \left\{1, \frac{\left|a_{0}\right|+\left|a_{1}\right|+\cdots+\left|a_{n-1}\right|}{\left|a_{n}\right|}\right\} .
$$

Now, let's come back to the inequality (8) with $k=2, \alpha_{1}:=\alpha$ and $\alpha_{2}:=\beta$. Take formally $n:=i$ in (8) to obtain

$$
a_{i+1} \leq \alpha a_{i}+\beta a_{i-1}+b_{i}
$$

then multiply both sides of this inequality by $u_{n-i}$ and sum up all the inequalities obtained for $i=1,2, \ldots, n$ to get

$$
0 \leq a_{n+1} \leq a_{1} u_{n}+\beta a_{0} u_{n-1}+\sum_{k=0}^{n-1} u_{k} b_{n-k}, \quad n \geq 1
$$

Now apply Lemma 1 to get the desired conclusion.

Remark 1 Note that for $k=1$, by Lemma 2 we obtain Theorem 2.1 in [37], a result which is fundamental for obtaining short proofs of stability theorems for one step fixed point iterative methods that has been used in $[12,13,15]$, and [17].

\section{Stability of $k$-step fixed point iteration procedures}

We first recall some concepts of stability for 1-step fixed point iteration procedures, before we consider the stability of a $k$-step fixed point iteration procedure.

Let $(X, d)$ be a metric space, $T: X \rightarrow X$ a self-operator with $\operatorname{Fix}(T) \neq \emptyset$ and let $\left\{x_{n}\right\}_{n=0}^{\infty}$ be a fixed point iteration procedure of the general form

$$
x_{n+1}=f\left(T, x_{n}\right), \quad n=0,1,2, \ldots,
$$

where $f\left(T, x_{n}\right)$ is given, which converges to a fixed point $p$ of $T$ (for example, in the case of Picard iteration we have $\left.f\left(T, x_{n}\right):=T x_{n}\right)$.

Definition 1 (Harder and Hicks, [3]) Let $\left\{y_{n}\right\}_{n=0}^{\infty}$ be an arbitrary sequence in $X$ and set

$$
\varepsilon_{n}=d\left(y_{n+1}, f\left(T, y_{n}\right)\right), \quad \text { for } n=0,1,2, \ldots
$$

We shall say that the fixed point iteration procedure (10) is T-stable or stable with respect to $T$ if

$$
\lim _{n \rightarrow \infty} \varepsilon_{n}=0 \Rightarrow \lim _{n \rightarrow \infty} y_{n}=p
$$

As Picard iteration and other fixed point iteration procedures are not stable with respect to some classes of contractive operators, various weak stability concepts have also been introduced; see [9, 11, 12, 15]. For example Osilike [9] introduced the concept of almost stability, while Berinde [12] introduced the concept of summable almost stability, two notions which are presented in the following. 
Definition 2 (Osilike, [9]) Let $(X, d)$ be a metric space, $T: X \rightarrow X$ a self-operator with $\operatorname{Fix}(T) \neq \emptyset$ and let $\left\{x_{n}\right\}_{n=0}^{\infty}$ be a fixed point iteration procedure given by (10), supposed to converge to a fixed point $p$ of $T$. Let $\left\{y_{n}\right\}_{n=0}^{\infty}$ be an arbitrary sequence in $X$ and let $\left\{\varepsilon_{n}\right\}$ be defined by (11). We shall say that the fixed point iteration procedure (10) is almost $T$-stable or almost stable with respect to $T$ if

$$
\sum_{n=1}^{\infty} \varepsilon_{n}<\infty \Rightarrow \lim _{n \rightarrow \infty} y_{n}=p
$$

Definition 3 (Berinde, [13]) Let $(X, d)$ be a metric space, $T: X \rightarrow X$ a self-operator with $\operatorname{Fix}(T) \neq \emptyset$ and let $\left\{x_{n}\right\}_{n=0}^{\infty}$ be a fixed point iteration procedure given by (10), supposed to converge to a fixed point $p$ of $T$. Let $\left\{y_{n}\right\}_{n=0}^{\infty}$ be an arbitrary sequence in $X$ and let $\left\{\varepsilon_{n}\right\}$ be defined by (11). We shall say that the fixed point iteration procedure (10) is summable almost $T$-stable or summable almost stable with respect to $T$ if

$$
\sum_{n=1}^{\infty} \varepsilon_{n}<\infty \Rightarrow \sum_{n=1}^{\infty} d\left(y_{n}, p\right)<\infty
$$

It is clear from Definitions 1-3 that:

(1) any stable iteration procedure is almost stable;

(2) any summable almost stable procedure is almost stable,

but the reverses of these assertions are not generally true; see Example 1 in [13]. Moreover, in general, the class of stable iteration procedures is independent of the class of summable almost stable procedures.

We introduce now the concept of stability for a $k$-step fixed point iteration procedure.

Definition 4 Let $(X, d)$ be a metric space, $k$ a positive integer, $T: X^{k} \rightarrow X$ a mapping with $\operatorname{Fix}(T)=\{x \in X: T(x, \ldots, x)=x\} \neq \emptyset$ and let $\left\{x_{n}\right\}_{n=0}^{\infty}$ be a $k$-step fixed point iteration procedure of the general form

$$
x_{n+1}=f\left(T, x_{n}, x_{n-1}, \ldots, x_{n-k+1}\right), \quad n=k-1, k, k+1, \ldots,
$$

which converges to a fixed point $p$ of $T$. Let $\left\{y_{n}\right\}_{n=0}^{\infty}$ be an arbitrary sequence in $X$ and set

$$
\varepsilon_{n}=d\left(y_{n+1}, f\left(T, y_{n}, y_{n-1}, \ldots, y_{n-k+1}\right)\right), \quad \text { for } n=k-1, k, k+1, \ldots
$$

We shall say that the fixed point iteration procedure (15) is $T$-stable or stable with respect to $T$ if

$$
\lim _{n \rightarrow \infty} \varepsilon_{n}=0 \Rightarrow \lim _{n \rightarrow \infty} y_{n}=p
$$

Remark 2 For $k=1$, by Definition 4 we get exactly Definition 1 .

The main result of this paper is the following theorem, which establish a stability result that corresponds to the fixed point theorem for Prešić-Kannan contractive mappings ([23], Theorem 2). 
Theorem 2 Let $(X, d)$ be a complete metric space, $k$ a positive integer, $a \in \mathbb{R}$ a constant such that $0<a k(k+1)<1$ and $T: X^{k} \rightarrow X$ a mapping satisfying the following contractive type condition:

$$
d\left(T\left(x_{0}, \ldots, x_{k-1}\right), T\left(x_{1}, \ldots, x_{k}\right)\right) \leq a \sum_{i=0}^{k} d\left(x_{i}, T\left(x_{i}, \ldots, x_{i}\right)\right)
$$

for any $x_{0}, x_{1}, \ldots, x_{k} \in X$.

Then:

(1) $T$ has a unique fixed point $x^{*}$, that is, there exists a unique $x^{*} \in X$ such that $T\left(x^{*}, \ldots, x^{*}\right)=x^{*}$

(2) The sequence $\left\{x_{n}\right\}_{n \geq 0}$ with $x_{0}, \ldots, x_{k-1} \in X$ and

$$
x_{n}=T\left(x_{n-k}, x_{n-k+1}, \ldots, x_{n-1}\right), \quad n \geq k
$$

converges to $x^{*}$;

(3) The $k$-step iteration $\left\{x_{n}\right\}_{n \geq 0}$ given by (19) is T-stable.

Proof Items (1) and (2) follow by Theorem 2 in [23]. Now let $\left\{y_{n}\right\}_{n=0}^{\infty}$ be an arbitrary sequence in $X$ and denote

$$
\varepsilon_{n}=d\left(y_{n+1}, T\left(y_{n}, y_{n-1}, \ldots, y_{n-k+1}\right)\right), \quad \text { for } n=k-1, k, k+1, \ldots
$$

First, by triangle inequality, we have

$$
d\left(y_{n+1}, x^{*}\right) \leq d\left(y_{n+1}, T\left(y_{n}, y_{n-1}, \ldots, y_{n-k+1}\right)\right)+d\left(T\left(y_{n}, y_{n-1}, \ldots, y_{n-k+1}\right), x^{*}\right) .
$$

In view of the contractive condition (18), we have

$$
\begin{aligned}
& d\left(T\left(y_{n}, y_{n-1}, \ldots, y_{n-k+1}\right), x^{*}\right) \\
&= d\left(T\left(y_{n}, \ldots, y_{n-k+1}\right), T\left(x^{*}, \ldots, x^{*}\right)\right) \\
& \leq d\left(T\left(y_{n}, \ldots, y_{n-k+1}\right), T\left(y_{n-1}, \ldots, y_{n-k+1}, x^{*}\right)\right) \\
&+d\left(T\left(y_{n-1}, \ldots, y_{n-k+1}, x^{*}\right), T\left(y_{n-2}, \ldots, y_{n-k+1}, x^{*}, x^{*}\right)\right) \\
&+\cdots+d\left(T\left(y_{n-k+1}, \ldots, x^{*}, x^{*}, x^{*}\right), T\left(x^{*}, \ldots, x^{*}, x^{*}, x^{*}\right)\right) .
\end{aligned}
$$

If we denote $F(x):=T(x, x, \ldots, x)$, then by the above inequality we get

$$
\begin{aligned}
d( & \left.T\left(y_{n}, y_{n-1}, \ldots, y_{n-k+1}\right), x^{*}\right) \\
\leq & a\left[d\left(y_{n}, T\left(y_{n}\right)\right)+\cdots+d\left(y_{n-k+1}, x^{*}\right)+d\left(x^{*}, x^{*}\right)\right] \\
& +a\left[d\left(y_{n-1}, T\left(y_{n-1}\right)\right)+\cdots+d\left(y_{n-k+1}, x^{*}\right)+d\left(x^{*}, x^{*}\right)+d\left(x^{*}, x^{*}\right)\right] \\
& +\cdots+a\left[d\left(y_{n-k+1}, T\left(y_{n-k+1}\right)\right)+d\left(x^{*}, x^{*}\right)+\cdots+d\left(x^{*}, x^{*}\right)\right] \\
= & a\left[d\left(y_{n}, T\left(y_{n}\right)\right)+2 d\left(y_{n-1}, T\left(y_{n-1}\right)\right)+\cdots+k d\left(y_{n-k+1}, T\left(y_{n-k+1}\right)\right)\right] .
\end{aligned}
$$


On the other hand, for any $j$ we have, by the triangle inequality,

$$
d\left(x_{j}, F\left(x_{j}\right)\right) \leq d\left(x_{j}, x^{*}\right)+d\left(x^{*}, F\left(x_{j}\right)\right) .
$$

Similarly to the way we obtained (22), we get for any $x, y \in X$,

$$
d(F(x), F(y))=d(T(x, x, \ldots, x), T(y, y, \ldots, y)) \leq A[d(x, F(x))+d(y, F(y))],
$$

where, by hypothesis, $A=\frac{a k(k+1)}{2}<\frac{1}{2}$.

Since $x^{*}$ is a fixed point of $T$, by taking $x:=x^{*}$ and $y:=x_{j}$ in (24) we have

$$
d\left(x^{*}, F\left(x_{j}\right)\right)=d\left(T\left(x^{*}, x^{*}, \ldots, x^{*}\right), T\left(x_{j}, x_{j}, \ldots, x_{j}\right)\right) \leq A d\left(x_{j}, F\left(x_{j}\right)\right) .
$$

Now, by (23) we get

$$
d\left(x_{j}, F\left(x_{j}\right)\right) \leq d\left(x_{j}, x^{*}\right)+A d\left(x_{j}, F\left(x_{j}\right)\right),
$$

that is,

$$
d\left(x_{j}, F\left(x_{j}\right)\right) \leq \frac{1}{1-A} d\left(x_{j}, x^{*}\right) .
$$

Now, by (21), (22), and (25) we find that the sequence of non-negative real numbers $\left\{d\left(y_{n}, x^{*}\right)\right\}$ satisfies the recurrence inequality

$$
d\left(y_{n+1}, x^{*}\right) \leq \alpha_{1} d\left(y_{n}, x^{*}\right)+\cdots+\alpha_{k} d\left(y_{n-k+1}, x^{*}\right)+\epsilon_{n}, \quad n \geq k-1,
$$

where $\alpha_{j}=\frac{j a}{1-A}$. It is a simple task to show that

$$
\alpha_{1}+\cdots+\alpha_{k}=\frac{a(1+2+\cdots+k)}{1-A}=\frac{A}{1-A}<1,
$$

since $A=\frac{a k(k+1)}{2}<\frac{1}{2}$, by hypothesis.

Now, assume $\lim _{n \rightarrow \infty} \varepsilon_{n}=0$. By applying Lemma 2 with $a_{n}:=d\left(y_{n}, x^{*}\right)$ and $b_{n}:=\varepsilon_{n}$, by virtue of (26), we conclude that $d\left(y_{n+1}, x^{*}\right) \rightarrow 0$ as $n \rightarrow \infty$, that is, the $k$-step iteration $\left\{x_{n}\right\}_{n \geq 0}$ defined by (19) is $T$-stable.

A similar stability result can be obtained for mappings $T$ satisfying a more general contractive condition than (18).

$$
\text { Denote } \operatorname{Fix}(T)=\{x \in X: T(x, x, \ldots, x)=x\} .
$$

Theorem 3 Let $(X, d)$ be a metric space, $k$ a positive integer and $T: X^{k} \rightarrow X$ a mapping with the property that $\operatorname{Fix}(T) \neq \emptyset$ for which there exist $\alpha_{1}, \alpha_{2}, \ldots, \alpha_{k} \in \mathbb{R}_{+}, \sum_{i=1}^{k} \alpha_{i}=\alpha<1$ satisfying

$$
d\left(T\left(x_{0}, \ldots, x_{k-1}\right), x^{*}\right) \leq \alpha_{1} d\left(x_{0}, x^{*}\right)+\cdots+\alpha_{k} d\left(x_{k-1}, x^{*}\right),
$$

for all $x_{0}, \ldots, x_{k-1} \in X$ and some $x^{*} \in \operatorname{Fix}(T)$. Then the $k$-step iteration $\left\{x_{n}\right\}_{n \geq 0}$ defined by (4) is T-stable. 
Proof Let $\left\{y_{n}\right\}_{n=0}^{\infty}$ be an arbitrary sequence in $X$ and denote

$$
\varepsilon_{n}=d\left(y_{n+1}, T\left(y_{n}, y_{n-1}, \ldots, y_{n-k+1}\right)\right), \quad \text { for } n=k-1, k, k+1, \ldots
$$

By triangle inequality, we have

$$
d\left(y_{n+1}, x^{*}\right) \leq d\left(y_{n+1}, T\left(y_{n}, y_{n-1}, \ldots, y_{n-k+1}\right)\right)+d\left(T\left(y_{n}, y_{n-1}, \ldots, y_{n-k+1}\right), x^{*}\right)
$$

and by (27) we obtain

$$
d\left(T\left(y_{n}, y_{n-1}, \ldots, y_{n-k+1}\right), x^{*}\right) \leq \alpha_{1} d\left(y_{n}, x^{*}\right)+\cdots+\alpha_{k} d\left(y_{n-k+1}, x^{*}\right)
$$

which together with (28) yields

$$
d\left(y_{n+1}, x^{*}\right) \leq \alpha_{1} d\left(y_{n}, x^{*}\right)+\cdots+\alpha_{k} d\left(y_{n-k+1}, x^{*}\right)+\epsilon_{n}, \quad n \geq k-1,
$$

and the rest of the proof is similar to that of Theorem 2.

Remark 3 It is clear by the proof of Theorem 2 that if $T$ satisfies (18) then $T$ also satisfies (27), but the reverse is not true, as shown by Example 2.

Another general stability result is given by the next theorem.

Theorem 4 Let $(X, d)$ be a metric space, $k$ a positive integer and $T: X^{k} \rightarrow X$ a mapping with the property that $\operatorname{Fix}(T) \neq \emptyset$ and for which there exist $\alpha_{1}, \alpha_{2}, \ldots, \alpha_{k} \in \mathbb{R}_{+}, \sum_{i=1}^{k} \alpha_{i}=\alpha<$ 1 and a constant $L>0$ such that

$$
\begin{aligned}
& d\left(T\left(x_{0}, \ldots, x_{k-1}\right), T(x, \ldots, x)\right) \\
& \quad \leq \alpha_{1} d\left(x_{0}, x\right)+\cdots+\alpha_{k} d\left(x_{k-1}, x\right)+L d(x, T(x, \ldots, x)),
\end{aligned}
$$

for all $x_{0}, \ldots, x_{k}, x \in X$. Then the $k$-step iteration $\left\{x_{n}\right\}_{n \geq 0}$ defined by (4) is T-stable.

Proof Let $\left\{y_{n}\right\}_{n=0}^{\infty}$ be an arbitrary sequence in $X$ and denote

$$
\varepsilon_{n}=d\left(y_{n+1}, T\left(y_{n}, y_{n-1}, \ldots, y_{n-k+1}\right)\right), \quad \text { for } n=k-1, k, k+1, \ldots
$$

If $x:=x^{*} \in \operatorname{Fix}(T)$ then by triangle inequality we get $(28)$ and by taking $x_{0}:=y_{n}, \ldots, x_{k-1}:=$ $y_{n-k+1}$ and $x:=x^{*} \in \operatorname{Fix}(T)$ in (30) we obtain

$$
d\left(T\left(y_{n}, y_{n-1}, \ldots, y_{n-k+1}\right), x^{*}\right) \leq \alpha_{1} d\left(y_{n}, x^{*}\right)+\cdots+\alpha_{k} d\left(y_{n-k+1}, x^{*}\right)
$$

since $x^{*}=T\left(x^{*}, \ldots, x^{*}\right)$. The rest of the proof follows similarly to the proof of Theorem 2 . 


\section{Examples and concluding remarks}

Example 1 ([23], Example 1) Let $X=[0,1]$ with the usual metric and $T: X^{2} \rightarrow X$ be defined by

$$
T(x, y)=\frac{1}{6}, \quad(x, y) \in\left[0, \frac{3}{4}\right) \times[0,1] ; \quad T(x, y)=\frac{1}{15}, \quad(x, y) \in\left[\frac{3}{4}, 1\right] \times[0,1] .
$$

Then, see the detailed proof in [23], $T$ satisfies (18) but does not satisfy (3), (6) and (7). Hence by Theorem 2 it follows that the $k$-step fixed point iteration (19) is $T$-stable.

To show that (18) holds, while (3), (6), (7) do not hold; see the detailed proof in [23].

Example 2 Let $X=\mathbb{R}$ with the usual metric and $T: X^{2} \rightarrow X$ be defined by

$$
T(x, y)=\frac{x+2 y}{4}, \quad \forall(x, y) \in X^{2} .
$$

It is easy to check that $T$ satisfies condition (3) (with $\alpha_{1}=\frac{1}{4}, \alpha_{2}=\frac{1}{2}$ ), condition (6) (with $\left.\varphi\left(t_{1}, t_{2}\right)=\frac{1}{4} t_{1}+\frac{1}{2} t_{2}\right)$, condition (7) (with $\lambda=\frac{3}{4}$ ) and condition (27) (with $\alpha_{1}=\frac{1}{4}, \alpha_{2}=\frac{1}{2}$ ) but does not satisfy (18).

Assume condition (18) does hold and take $x_{0}:=\frac{1}{2}, x_{1}:=\frac{1}{2}$ and $x_{2}:=0$. We get

$$
\frac{1}{4} \leq \frac{a}{4} \quad \Leftrightarrow \quad 1 \leq a
$$

a contradiction, since, by hypothesis, $a<\frac{1}{6}$. Hence by Theorem 3 or Theorem 4 (but not by Theorem 2) it follows that the $k$-step fixed point iteration (19) is $T$-stable.

The next example illustrates unstable fixed point iterations, in the case neither (18) nor (27) is satisfied.

Example 3 Consider the case $k=1$ (in order to graph the orbits), $X=\left[-\frac{3}{2}, \frac{1}{2}\right]$ with the Euclidean norm and let $T: X \rightarrow X$ be given by $T x=2 x^{2}+2 x-1$, for all $x \in X$.

Then $T$ does not satisfy (3), (18), (27), and (30), $\operatorname{Fix}(T)=\left\{-1, \frac{1}{2}\right\}$ and the orbits of $x_{0}=$ 0.49 under $T$ behave chaotic; see Figure 1.

Indeed, assume that (3) holds, i.e.,

$$
|T x-T y| \leq \alpha_{1}|x-y|, \quad \forall x, y \in X,
$$

and take $x=-\frac{3}{2}, y=-1$ to get the contradiction $3 \leq \alpha_{1}<1$. For the same values of $x$ and $y$, (18) and (30) are not satisfied. Now, assume that (27) holds for $x^{*}=-1$, i.e.,

$$
|T x+1| \leq \alpha_{1}|x+1|, \quad \forall x \in X,
$$

and take $x=0$, to get the contradiction $1 \leq \alpha_{1}<1$.

Note that for $x_{0}=0.5$ we obtain a convergent (and constant) sequence, $x_{n}=0.5, n \geq 0$, while for $x_{0}$ as close as possible to 0.5 but different of 0.5 we have always unstable orbits $\left\{x_{n}\right\}$. 


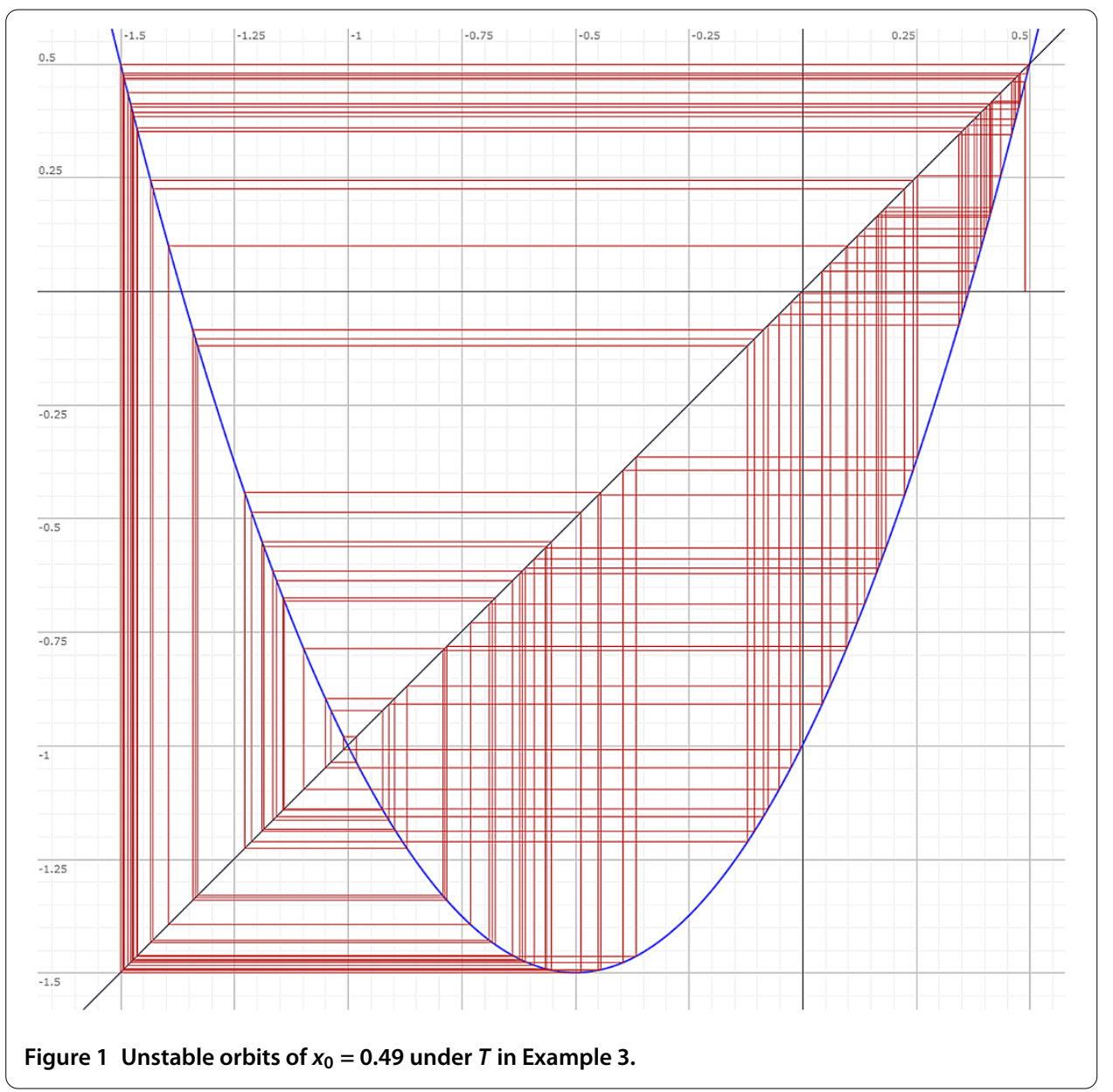

Similar approaches to those in the present paper can be done for mappings defined on product spaces but adapted from the ones in the usual case; see the recent related fixed point results [38-42], and [43].

\section{Competing interests}

The authors declare that they have no competing interests.

Authors' contributions

The authors read and approved the final manuscript.

\section{Author details}

'Department of Mathematics and Computer Science, North University of Baia Mare, Victorie1 76, Baia Mare, 430072, Romania. ${ }^{2}$ Department of Statistics, Analysis, Forecast and Mathematics, Faculty of Economics and Bussiness Administration, Babeş-Bolyai University of Cluj-Napoca, 56-60 T. Mihali St., Cluj-Napoca, 400591, Romania.

\section{Acknowledgements}

The authors research was supported by the Grant PN-II-RU-TE-2011-3-239 of the Romanian Ministry of Education and Research. The first author was also supported by the Grant PN-II-ID-PCE-2011-3-0087 of the Romanian Ministry of Education and Research.

\section{Received: 7 December 2013 Accepted: 28 March 2014 Published: 11 Apr 2014}

\section{References}

1. Jachymski, JR: An extension of A. Ostrowski's theorem on the round-off stability of iterations. Aequ. Math. 53(3), 242-253 (1997)

2. Ostrowski, AM: The round-off stability of iterations. Z. Angew. Math. Mech. 47, 77-81 (1967)

3. Harder, AM, Hicks, TL: A stable iteration procedure for nonexpansive mappings. Math. Jpn. 33(5), 687-692 (1988)

4. Harder, AM, Hicks, TL: Stability results for fixed point iteration procedures. Math. Jpn. 33(5), 693-706 (1988) 
5. Rhoades, BE: Fixed point theorems and stability results for fixed point iteration procedures. Indian J. Pure Appl. Math. 21(1), 1-9 (1990)

6. Rhoades, BE: Some fixed point iteration procedures. Int. J. Math. Math. Sci. 14(1), 1-16 (1991)

7. Rhoades, BE: Fixed point theorems and stability results for fixed point iteration procedures. II. Indian J. Pure Appl. Math. 24(11), 691-703 (1993)

8. Osilike, MO: Stability results for fixed point iteration procedures. J. Niger. Math. Soc. 14/15, 17-29 (1995/1996)

9. Osilike, MO: Stability of the Mann and Ishikawa iteration procedures for $\phi$-strong pseudocontractions and nonlinear equations of the $\phi$-strongly accretive type. J. Math. Anal. Appl. 227(2), 319-334 (1998)

10. Osilike, MO, Udomene, A: Short proofs of stability results for fixed point iteration procedures for a class of contractive-type mappings. Indian J. Pure Appl. Math. 30(12), 1229-1234 (1999)

11. Zhou, HY, Chang, S-S, Cho, YJ: Weak stability of the Ishikawa iteration procedures for $\phi$-hemicontractions and accretive operators. Appl. Math. Lett. 14(8), 949-954 (2001)

12. Berinde, V: On the stability of fixed point iteration procedures. Bul. Ştiinţ. - Univ. Baia Mare, Ser. B Fasc. Mat.-Inform. 18(1), 7-12 (2002)

13. Berinde, V: Summable almost stability of fixed point iteration procedures. Carpath. J. Math. 19(2), 81-88 (2003)

14. Imoru, C, Olatinwo, MO: On the stability of Picard and Mann iteration processes. Carpath. J. Math. 19(2), 155-160 (2003)

15. Berinde, V: Iterative Approximation of Fixed Points. Springer, Berlin (2007)

16. Qing, Y, Rhoades, BE: T-stability of Picard iteration in metric spaces. Fixed Point Theory Appl. 2008, Article ID 418971 (2008)

17. Olatinwo, MO: Some stability results in complete metric space. Acta Univ. Palacki. Olomuc., Fac. Rerum Nat., Math. 48 83-92 (2009)

18. Rus, IA: An abstract point of view on iterative approximation of fixed points: impact on the theory of fixed point equations. Fixed Point Theory 13(1), 179-192 (2012)

19. Rus, IA: Properties of the solutions of those equations for which Krasnoselskii iteration converges. Carpath. J. Math 28(2), 329-336 (2012)

20. Prešić, SB: Sur une classe d'inéquations aux différences finites et sur la convergence de certaines suites. Publ. Inst. Math. (Belgr.) 5(19), 75-78 (1965)

21. Cirić, LB, Prešić, SB: On Prešić type generalization of the Banach contraction mapping principle. Acta Math. Univ. Comen. 76(2), 143-147 (2007)

22. Păcurar, M: Iterative Methods for Fixed Point Approximation, Risoprint, Cluj-Napoca (2010)

23. Păcurar, M: A multi-step iterative method for approximating fixed points of Prešić-Kannan operators. Acta Math. Univ. Comen. 79(1), 77-88 (2010)

24. Păcurar, M: Approximating common fixed points of Prešić-Kannan type operators by a multi-step iterative method. An. Univ. "Ovidius" Constanţa, Ser. Mat. 17(1), 153-168 (2009)

25. Păcurar, M: Fixed points of almost Prešić operators by a k-step iterative method. An. Ştiinţ. Univ. 'Al.I. Cuza' laşi, Mat. 57, 199-210 (2011)

26. Rus, IA: An iterative method for the solution of the equation $x=f(x, \ldots, x)$. Rev. Anal. Numér. Théor. Approx. 10(1), 95-100 (1981)

27. Berinde, V, Păcurar, M: An iterative method for approximating fixed points of Prešić nonexpansive mappings. Rev Anal. Numér. Théor. Approx. 38(2), 144-153 (2009)

28. Berinde, V, Păcurar, M: Two elementary applications of some Prešić type fixed point theorems. Creative Math. Inform. 20(1), 32-42 (2011)

29. Chen, Y-Z: A Prešić type contractive condition and its applications. Nonlinear Anal. 71, e2012-e2017 (2009)

30. Păvăloiu, I: Rezolvarea ecuațiilor prin interpolare. Editura Dacia, Cluj-Napoca (1981)

31. Păvăloiu, I, Pop, N: Interpolare şi aplicaţii. Risoprint, Cluj-Napoca (2005)

32. Berinde, V, Păcurar, M: O metodă de tip punct fix pentru rezolvarea sistemelor ciclice. Gaz. Mat., Ser. B 116(3), 113-123 (2011)

33. Păcurar, M: A multi-step iterative method for approximating common fixed points of Prešić-Rus type operators on metric spaces. Stud. Univ. Babeş-Bolyai, Math. 55(1), 149-162 (2010)

34. Berinde, $\mathrm{V}$ : A note on a difference inequality used in the iterative approximation of fixed points. Creative Math. Inform. 18(1), 6-9 (2009)

35. Rus, IA, Şerban, MA: Some generalizations of a Cauchy lemma and applications. In: Cobzas, S (ed.) Topics in Mathematics, Computer Science and Philosophy, pp. 173-181. Cluj University Press, Cluj-Napoca (2008)

36. Wikipedia: Properties of polynomial roots. http://en.wikipedia.org/wiki/Properties of polynomial_roots

37. Berinde, $\mathrm{V}$ : On a family of first order difference inequalities used in the iterative approximation of fixed points. Creative Math. Inform. 18(2), 110-122 (2009)

38. Berinde, $\mathrm{V}$ : Convergence theorems for fixed point iterative methods defined as admissible perturbations of a nonlinear operator. Carpath. J. Math. 29(1), 9-18 (2013)

39. Choban, MM: Fixed points for mappings defined on pseudometric spaces. Creative Math. Inform. 22(2), 173-184 (2013)

40. Harjani, J, Sabetghadam, F, Sadarangani, K: Fixed point theorems for cyclic weak contractions in partially ordered sets endowed with a complete metric. Carpath. J. Math. 29(2), 179-186 (2013)

41. Păcurar, M: Common fixed points for almost Prešić type operators. Carpath. J. Math. 28(1), 117-126 (2012)

42. Popa, V: On some fixed point theorems for implicit almost contractive mappings. Carpath. J. Math. 29(2), 223-229 (2013)

43. Rus, IA, Serban, M-A: Basic problems of the metric fixed point theory and the relevance of a metric fixed point theorem. Carpath. J. Math. 29(2), 239-258 (2013)

10.1186/1029-242X-2014-149

Cite this article as: Berinde and Păcurar: Stability of k-step fixed point iterative methods for some Prešić type contractive mappings. Journal of Inequalities and Applications 2014, 2014:149 